\title{
Inclusão de estudantes com deficiência no ensino superior: uma revisão sistemática
}

\author{
Rosamaria Reo Pereira* \\ Simone Souza da Costa Silva** \\ Rosana Assef Faciola*** \\ Fernando Augusto Ramos Pontes*** \\ Maély Ferreira Holanda Ramo*****
}

\section{Resumo}

O presente estudo tem como objetivo analisar a produção científica acerca da inclusão de estudantes com deficiência no ensino superior. A metodologia adotada foi uma revisão sistemática da literatura na base de dados dos Periódicos da Coordenação de Aperfeiçoamento de Pessoal de Nível Superior - CAPES, entre o período de 2003 e 2013. As buscas resultaram em 22 artigos cujos resultados foram submetidos à técnica de análise e visualização de dados com grafos. Dentre as variáveis analisadas, destacam-se aspectos relativos à acessibilidade, tecnologia virtual, capacitação de professores, reforma educacional, entre outros. Os resultados orientam a elaboração de práticas inclusivas que fortaleçam os serviços disponibilizados aos estudantes universitários com deficiência. Palavras-chave: Ensino superior; Educação inclusiva; Estudante com deficiência.

Palavras-chave: Ensino superior; Educação inclusiva; Estudante com deficiência.

\footnotetext{
* Doutoranda do Programa de Pós-Graduação em Teoria e Pesquisa do Comportamento da Universidade Federal do Pará, Belém, Pará, Brasil.

** Doutora do Programa de Pós-Graduação em Teoria e Pesquisa do Comportamento da Universidade Federal do Pará, Belém, Pará, Brasil.

**** Doutora da Faculdade de Letras Estrangeiras Modernas da Universidade Federal do Pará, Belém, Pará, Brasil.

**** Doutor do Programa de Pós-Graduaçáo em Teoria e Pesquisa do Comportamento da Universidade Federal do Pará, Belém, Pará, Brasil.

***** Doutora do Programa de Pós-Graduação em Educação da Universidade Federal do Pará, Belém, Pará, Brasil.
} 


\section{Inclusion of students with disability in higher education: a systematic review}

\section{Abstract}

The present study aims to analyze the scientific production on the inclusion of students with disabilities in higher education. The methodology used was a systematic review of the literature on the database journals of CAPES, from 2003 to 2013. The research resulted in 22 articles. They were submitted to technical analysis and data visualization with graphs. Among the variables analyzed, aspects such as accessibility, virtual technology, teacher training, educational reform, among others were mentioned. The results guide the development of inclusive practices that strengthen the services provided to students with disabilities in higher education institutions.

Keywords: Higher education; Inclusive education; Student with disabilities.

\section{Introdução}

A inclusão é um movimento educacional, social e político que defende o direito de todas as pessoas a participarem da sociedade e de serem respeitados naquilo que os diferencia dos outros. No contexto educacional, a inclusão defende o direito dos estudantes a se desenvolverem e concretizarem as suas potencialidades, bem como de se apropriarem das competências que lhes permitam exercer o seu direito por meio de uma educação de qualidade, atendendo, assim, as suas necessidades, interesses e características (FREIRE, 2008). A escola inclusiva, segundo Aranha (2004, p. 7), "é aquela que garante a qualidade de ensino educacional a cada um de seus alunos, reconhecendo e respeitando a diversidade e respondendo a cada um de acordo com suas potencialidades e necessidades".

Assim, as transformaçóes ocorridas no sistema educacional inclusivo a partir das décadas de 70, 80 e 90 modificaram o paradigma da concepçáo de escola para uma educaçáo inclusiva, o qual consiste em açóes políticas, culturais, sociais e pedagógicas que promovem o direito dos cidadãos com deficiência de poderem compartilhar juntos, aprendendo e participando, sem nenhum tipo de discriminação e/ou constrangimento. A educação inclusiva, segundo Fischer (2010), é consequência de um movimento mundial, onde organizaçôes, líderes políticos, educadores e pessoas com deficiência têm uma participação efetiva.

Neste contexto, algumas conferências internacionais começaram a repercutir diretamente na educação inclusiva. Destaca-se a Conferência Mundial de Educação para Todos, organizada pela Organizaçáo das Naçóes Unidas para a Educaçáo, a Ciência e a Cultura (Unesco), ocorrida em 1990, em Jomtien, na Tailândia. Desta reunião surgiu a Declaração Mundial sobre Educação para Todos e teve por objetivo estabelecer princípios, diretrizes e normas que direcionaram as reformas educacionais em vários países (Unesco, 1990). 
A Conferência Mundial sobre Necessidades Educativas Especiais, de 1994, em Salamanca, na Espanha, reafirma o compromisso em prol da Educaçâo para Todos e da necessidade de garantir o ingresso de todas as pessoas com deficiência no sistema regular de educação. Esta conferência gerou a Declaração de Salamanca (UNESCO, 1994), que defende a inclusão e afirma que "cada criança tem o direito fundamental à educação e deve ter a oportunidade de conseguir e manter um nível aceitável de aprendizagem" (alínea 1).

A Declaração Mundial sobre Educação Superior no Século XXI, aprovada na Conferência Mundial sobre Educação Superior, em 1998, estabelece as missões e funçóes do ensino superior, açôes necessárias e as prioridades no âmbito dos sistemas e das instituiçôes. Esta declaração determina a igualdade de acesso a este nível de ensino (UNESCO, 1999).

Já a Convenção Internacional das Pessoas com Deficiência, de 2006, assegura a acessibilidade aos deficientes aos meios físico, social, econômico e cultural de forma a reduzir tais dificuldades. O art. XXIV trata de forma específica do direito das pessoas com deficiência à educação. No entanto, é necessário a capacitação dos estabelecimentos educacionais com adaptaçóes necessárias e específicas para cada tipo de deficiência, assim como a adoçáo de medidas de apoio individualizantes em todos os níveis de ensino (ONU, 2006).

\section{Educação inclusiva na universidade}

Um dos papeis das instituições de ensino superior é incentivar a geração de conhecimento por meio de pesquisas e também conscientizar a populaçáo acadêmica sobre a importância da valorizaçáo do ser humano, inclusive daqueles com deficiência, facilitando o ingresso dessas pessoas no mercado de trabalho, contribuindo, assim, para que elas ocupem seu lugar na sociedade.

O estudante com deficiência busca conhecimento e formação acadêmica e profissional ao ingressar em uma universidade, e esta, por outro lado, enquanto espaço social e educacional, deve reafirmar seu compromisso com uma educação de qualidade, com direito à cidadania, a justiça social e a democracia, assumindo, desta maneira, um papel fundamental no crescimento pessoal e acadêmico do estudante e o dever de oportunizar a educação para todos.

Neste sentido, o interesse em conhecer a produção científica internacional acerca da inclusão do aluno com deficiência no ensino superior motivou os autores deste estudo a realizarem uma revisão sistemática da literatura para compreender como a inclusão de universitários com deficiência está de fato ocorrendo. Tal objetivo visa identificar, nos estudos selecionados, os pontos que favorecem e os pontos que interferem neste processo, revelando dados que poderẫo auxiliar as instituiçóes a se tornarem proativas em relaçáo à inclusão. Assim, busca-se descrever o panorama das pesquisas sobre a inclusão do estudante com deficiência nos estabelecimentos de ensino superior a partir de 22 artigos publicados no período de 2003 a 2013, no banco de dados dos Periódicos/CAPES, utilizando técnicas de análise e visualização de dados com grafos. 


\section{Método}

Este estudo consiste em uma revisão sistemática da literatura acerca da inclusão do estudante com deficiência no ensino superior. O primeiro passo foi estabelecer a pergunta: qual o panorama das pesquisas sobre a inclusão de estudantes com deficiência nas instituições de ensino superior? No segundo passo, foram considerados os seguintes descritores para a localização dos artigos: higher education, handicapped students, disabled, university, disabled students, disabilities, students with disabilities, inclusion. Recorreu-se aos operadores lógicos "AND" e "OR" para combinação das palavras-chave. Os artigos foram selecionados a partir da ferramenta de busca da biblioteca virtual da CAPES/Periódico. Foram adotados os seguintes critérios de inclusão: artigos completos, empíricos e com métodos quantitativos disponibilizados online, publicados entre 2003 e 2013, no idioma inglês, ter sido revisado por pares e ter como foco a inclusão do estudante com deficiência no ensino superior. Os critérios de exclusão foram: artigos repetidos, empíricos com métodos qualitativos, teóricos, indisponíveis ou com problemas de exibição, que não tratam da inclusão do aluno com deficiência no ensino superior e que não possuem palavras-chave.

Após o refinamento inicial, um Teste de Relevância baseado em Azevedo (2010) foi realizado. O teste foi aplicado aos artigos na íntegra por dois juízes com conhecimento na área e foi composto por perguntas que geravam respostas afirmativas ou negativas nos seguintes aspectos: o objetivo do estudo está bem definido? A metodologia está claramente descrita? A investigação possui metodologia adequada? Os resultados encontrados revelam dados importantes para que a inclusão do estudante com deficiência na universidade seja efetivada? As conclusóes podem ser consideradas relevantes no que diz respeito à inclusão do estudante com deficiência no ensino superior?

Após a aplicação do Teste de Relevância, iniciou-se a delimitação das variáveis a serem investigadas e posterior coleta de dados. Para a análise, foram utilizados os seguintes programas: (1) EXCEL 2010 para a organização dos dados e relacionamento das variáveis; (2) NodeXL para construção de grafos.

Um grafo consiste num conjunto finito e não vazio de vértices e arestas. Os vértices representam os elementos de qualquer fenômeno que são ligados por arestas que indicam qualquer relação entre os vértices. Neste estudo, todos os grafos são multigrafos dirigidos onde ocorre a existência de conexôes duplas ou múltiplas entre um mesmo par de elementos, indicando que por mais de uma vez uma determinada relação ocorreu entre variáveis distintas do banco de dados selecionado. Num multigrafo direcionado, as relaçôes são direcionadas por setas, havendo um vértice de origem e um outro de destino (RAMOS; COSTA; PONTES, 2014 - em produção).

Para análise das relações entre as variáveis investigadas pelos artigos com grafos no NodeXL, as seguintes métricas foram calculadas, a saber: (1) Grau de Centralidade (in-degreelout-degree) - para quantificar o número de ligaçóes associadas a um elemento; (2) Relevância do Vértice (PageRank) - para medir o grau de importância de um vértice (RAMOS; COSTA; PONTES, 2014 - em produção). Após a organização e análise dos dados, o processo de interpretação das informaçôes e posterior construção e aprimoramento da revisão sistemática foram realizados. 


\section{Resultados}

O processo de levantamento resultou em 572 objetos. Na Tabela 1 é apresentado o resultado do processo de refinamento inicial.

Tabela 1 - Processo de Refinamento inicial dos Artigos.

\begin{tabular}{l|c}
\hline Base de dados & CAPES \\
\hline Total inicial & 572 \\
\hline $\begin{array}{l}\text { Não tratam da inclusão do aluno com deficiência no } \\
\text { ensino superior }\end{array}$ & 358 \\
\hline Teóricos e empíricos com método qualitativo & 65 \\
\hline Repetidos & 78 \\
\hline Não disponíveis & 14 \\
\hline Não possuem palavras-chave & 28 \\
\hline Refinamento Inicial & 29 \\
\hline
\end{tabular}

Os resultados indicam que 95\% dos artigos foram excluídos. Assim, 5\% dos 572 foram considerados válidos por atenderem todos os critérios de inclusão. Sequencialmente, os 29 estudos restantes foram submetidos à avaliação, sob os critérios do Teste de Relevância, destes, 7 artigos foram excluídos por apresentarem problemas relacionados à clareza dos métodos de estudo. 22 artigos permaneceram no banco de dados da revisão sistemática.

\section{Relações entre as variáveis investigadas nos estudos}

Para o estudo das relaçóes entre as variáveis indicadas nos resultados dos artigos investigados, utilizou-se a ferramenta NodeXL. Os multigrafos estão organizados em duas classes de estudos quantitativos, a saber: correlaçóes positivas e correlaçóes negativas. Para representar os estudos quantitativos, escolheu-se explorar as correlaçóes positivas (Figura 1) e as correlaçóes negativas (Figura 2), pois esta técnica estatística de delineamento correlacional é bastante utilizada nos artigos com abordagem quantitativa. Ressalta-se que as métricas calculadas pelo NodeXL não indicam escores de correlação como resultado de análise estatística, apontam apenas grau de relevância e de centralidade de determinada variável (identificada como vértice) em relação as outras variáveis no corpo de dados consequentes da análise conjunta dos resultados dos artigos.

Para melhor interpretar os multigrafos (Figuras 1 e 2), deve-se considerar que: (1) correlações positivas - cada vez que $\mathrm{x}$ aumenta, y aumenta um determinado valor de forma constante; (2) correlaçôes negativas - cada vez que x aumenta, y diminui um valor de forma constante. Ressalta-se que, quando uma seta é divergente de um vértice, isto significa que a relação parte deste vértice, $\mathrm{X} \rightarrow \mathrm{Y}$. No caso de arestas bidirecionais, as setas indicam uma relação mútua entre as variáveis.

No caso de arestas duplas e/ou múltiplas entre um mesmo par de vértices, as setas dispóem-se de forma sobreposta. Em termos de visualização, quanto mais larga 
for a aresta, maior será o número de setas ligando os pontos. Ressalta-se que cada aresta representa a ocorrência de uma determinada relação num artigo.

\section{Análise das correlações positivas}

Para sintetizar os resultados dos artigos investigados quanto às correlaçóes positivas entre as variáveis dos estudos, foram ressaltados, por ordem de centralidade, os vértices mais importantes, a saber: (1) esperança; (2) performance acadêmica e social; (3) persistência; (4) estudantes com deficiência; (5) conclusão de curso (Figura 1).

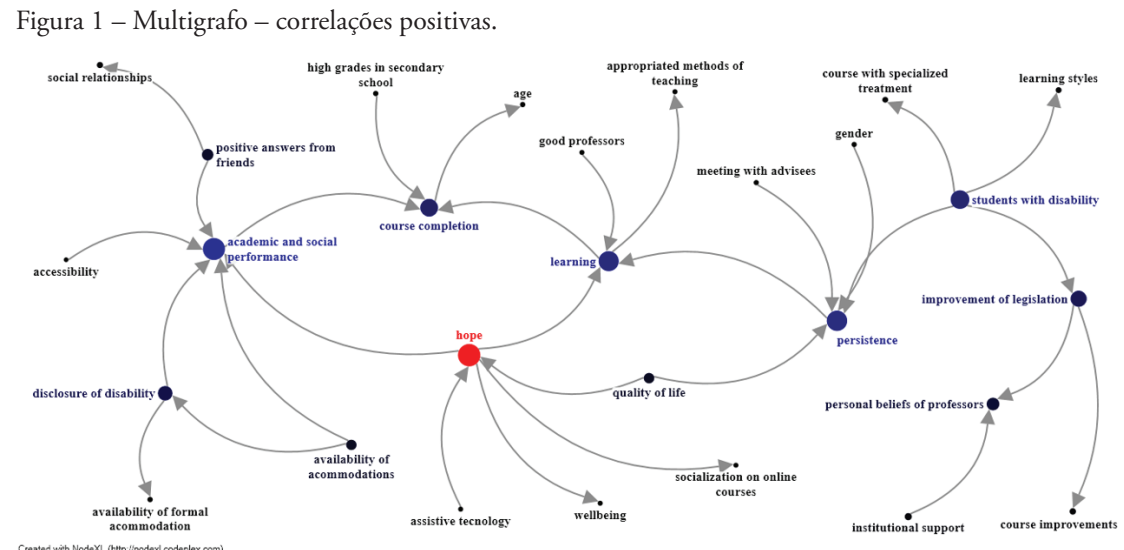

Os vértices principais foram representados no multigrafo por círculos em escalas de tons azuis e postos em destaque, quanto mais claro for o tom de azul, mais importante é o vértice. $\mathrm{O}$ disco vermelho destaca o vértice mais importante. Realizou-se um mapeamento dos resultados das correlaçôes realizadas pelos artigos. Para a seleção dos elementos mais importantes deste subgrafo, considerou os vértices com PageRank > 0,062.

O vértice mais importante do multigrafo (Figura 1) foi esperança (disco vermelho), pois alcançou o escore mais elevado de PageRank deste agrupamento $(2,5)$, conectando-se a 6 outros vértices. $O$ vértice esperança está correlacionado positivamente com os vértices bem estar, socialização de cursos online e aprendizagem. Observou-se esta correlação no estudo de Heiman e Shemesh (2012), quando os autores examinaram a percepção de 964 universitários com deficiência de aprendizagem acerca da esperança e de como esse sentimento está positivamente relacionado ao bem estar, à aprendizagem e à socializaçáo de cursos online. Eles concluíram que os alunos com deficiência acessam frequentemente os sites de cursos online, participam de fóruns e deixam significativamente inúmeras mensagens, assim como estão bem familiarizados com a tecnologia assistiva.

$\mathrm{O}$ vértice tecnologia assistiva está positivamente relacionado com a variável esperança, pois proporciona aos alunos várias formas de adaptação, permitindo-lhes ganhar acesso aos materiais de estudo e informaçóes, diminuindo as barreiras acadêmicas no aprendizado. $\mathrm{O}$ que sugere que o ganho na qualidade de vida que os alunos 
recebem com este serviço oferecido pelas instituições tem um efeito positivo na esperança de obter sucesso no curso desejado (HEIMAN; SHEMESH, 2012).

O segundo vértice mais importante foi performance acadêmica e social, alcançando o escore 2,4 na métrica PageRank e conectando-se também a seis outros vértices do multigrafo. O vértice performance acadêmica e social foi correlacionado positivamente com o vértice conclusão de curso. Neste sentido, o trabalho de Richardson (2010) comparou os resultados obtidos da taxa de conclusão de curso dos alunos com e sem deficiência que frequentaram os cursos de ensino à distância da Universidade Aberta do Reino Unido e constatou que estudantes com deficiência com mais idade e com notas elevadas no ensino médio tiveram um bom desempenho acadêmico ao concluirem o curso superior.

$\mathrm{O}$ vértice revelação da deficiência está correlacionado positivamente com os vértices performance acadêmica e social e com a disponibilidade de acomodaçôes. Observou-se tal correlação no estudo de Brak, Lechenberger e Lan (2010), que tiveram por objetivo conhecer a percepçáo dos acadêmicos acerca de como eles divulgam informaçóes confidenciais sobre suas deficiências para os professores e demais funcionários a fim de receberem acomodaçóes formais em sala de aula. Os autores concluiram que alunos com deficiência que são academicamente bem sucedidos adotam algumas estratégias ao requerer acomodaçóes ao ingressar no ensino superior. Isso sugere que escrever uma carta onde consta a descrição ou revelação da deficiência e/ou do tipo de acomodação que o acadêmico vai precisar em sala de aula consiste em estratégia que está positivamente relacionada ao desempenho acadêmico e social do aluno.

$\mathrm{O}$ vértice disponibilidade de acomodação está correlacionado positivamente com os vértices performance acadêmica e social e com a revelação da deficiência. Tal correlação foi observada no estudo de Quinlan, Bates e Angell (2012), quando investigaram a percepçáo de estudantes com deficiência de aprendizagem acerca de como os professores oferecem acomodaçóes e como eles podem criar espaços para um aprendizado transformador. Analisando os temas que surgiram nos questionários, a disponibilidade de acomodação foi correlacionada positivamente com a revelação da deficiência e com o desempenho social e acadêmico do estudante.

Os vertíces acessibilidade e as respostas positivas dos colegas estão correlacionados positivamente com o desempenho acadêmico e social de estudantes com deficiência. Neste sentido, o estudo de Hadjikakou, Polycarpou e Hadjilia (2010) investigou as percepçóes de dez estudantes com deficiência de instituiçóes de ensino superior de Cypriot acerca do acesso físico na universidade e do bom relacionamento com os colegas. Metade dos participantes mencionou que as instituiçôes tinham um bom acesso e que eles poderiam facilmente chegar às diferentes salas dentro da universidade. Em relação ao vértice experiências sociais, a maioria dos participantes apontou que eles tinham desenvolvido boas relaçôes com seus colegas não deficientes.

O terceiro vértice mais importante foi persistência, pois esta é a variável que apresenta maior escore PageRank deste agrupamento $(2,1)$, conectou a 5 outros vértices. Os vértices ser do sexo feminino, ter encontros com os orientadores, assim como 
ter uma boa qualidade de vida estáo positivamente correlacionado com a variável persistência.

A persistência de alunos com deficiência no ensino superior foi considerada como um fator positivo no aprendizado dos mesmos. Mamiseishvili e Kock (2011) examinaram as características de estudantes universitários com deficiência e os fatores que influenciaram na persistência dos mesmos na passagem do primeiro para o segundo ano da graduação. Observou-se que a vontade de estudar, ser do sexo feminino, ter encontros frequentes com os orientadores e ter uma boa qualidade de vida foram considerados como fatores preponderantes na persistência do aluno com deficiência no ensino superior.

O quarto vértice mais importante do multigrafo de correlaçóes positivas foi estudantes com deficiência, com escore PageRank $(1,8)$, houve conexão direta com 4 vértices. $\mathrm{O}$ vértice alunos com deficiência tem uma relação positiva com os vértices estilos de aprendizagem, cursos com apoio especializado, melhoramento na legislaçâo e com persistência. Com o objetivo de verificar a associação entre dislexia e um estilo de aprendizagem sensorial específica ou não, Stampoltzis et al. (2010) analisaram a relação entre a dislexia, as modalidades sensoriais de aprendizagem e as características educacionais por meio da percepção de estudantes universitários disléxicos. Os autores do estudo concluíram que os acadêmicos disléxicos têm uma relação positiva com o estilo de aprendizagem sinestésica.

No estudo de Taylor, Baskett e Wren (2010), o aluno com deficiência tem relação positiva com cursos de graduação que oferecem apoio especializado aos deficientes. Nas universidades investigadas, todos os estudantes que declararam alguma deficiência em seu formulário de matrícula foram entrevistados pelo pessoal de apoio na área da inclusão da universidade. A finalidade foi verificar o nível de deficiência do aluno e desenvolver um plano para apoiá-lo ao longo do seu curso.

Em relação às políticas públicas, Riddell et al. (2007) constataram que os melhoramentos na legislação vigente têm um efeito positivo nas crenças pessoais dos professores e nos ajustes tanto no currículo como nos exames realizados nos cursos de graduaçáo oferecidos aos alunos com deficiência. Neste estudo, apesar de alguns professores não se envolverem em açóes e projetos que venham melhorar os serviços oferecidos aos estudantes, a maioria acredita que náo devem descriminar esses alunos, pois eles têm o direito garantido por lei de receber os mesmos benefícios que qualquer outro aluno sem deficiência.

Segundo Zhang et al. (2010), o apoio institucional influencia diretamente a crença pessoal dos professores em relação aos alunos com deficiência. Eles acreditam que, com o apoio necessário da instituição, eles estarão preparados para receberem esses alunos em seus programas. Atividades, cursos, workshops podem ser organizados pela instituição com o objetivo de aumentar o nível de conforto dos docentes para interagir com e ensinar os alunos com deficiência, de modo que todos os medos, mitos, crenças ou mal-entendidos que eles possam ter para com os universitários com deficiência sejam desmistificados. 
O quinto vértice mais importante foi conclusão de curso, com escore PageRank de $(1,7)$. Conectou-se a 4 outros diferentes vértices do multigrafo. O vértice conclusão de curso está correlacionado positivamente com os vértices idade e a obtenção de notas elevadas no ensino médio, assim como à conclusão do curso na universidade. Esta correlação foi observada por Richardson (2010), quando comparou os resultados obtidos da taxa de conclusão de curso dos alunos com e sem deficiência que frequentaram os cursos de ensino à distância da Universidade Aberta do Reino Unido e constatou que alunos com deficiência com mais idade e com notas elevadas no ensino médio são propensos a concluírem o curso superior.

$\mathrm{O}$ vértice aprendizagem está correlacionado positivamente com os vértices conclusão de curso e com métodos apropriados de ensino. A variável bons professores está positivamente correlacionada com o vértice aprendizagem. Neste sentido, o estudo de Hadjikakou et al. (2010) revelou que os docentes não estão plenamente capacitados para lidar com alunos com deficiência, no entanto, foram positivamente relacionados com o ensino e aprendizagem dos estudantes. Isto significa que a percepção dos discentes em relaçấo aos professores foi muito boa, pois os estudantes com deficiência acreditam que os docentes se esforçam para contribuir com o sucesso acadêmico dos mesmos.

\section{Análise das correlações negativas}

Para sintetizar os resultados dos artigos investigados quanto às correlaçóes negativas entre as variáveis dos estudos, foram ressaltados, por ordem de centralidade, os vértices mais importantes, a saber: (1) estudantes com deficiência; (2) percepção da qualidade acadêmica (Figura 2).

Figura 2 - Multigrafo - Correlaçōes negativas.

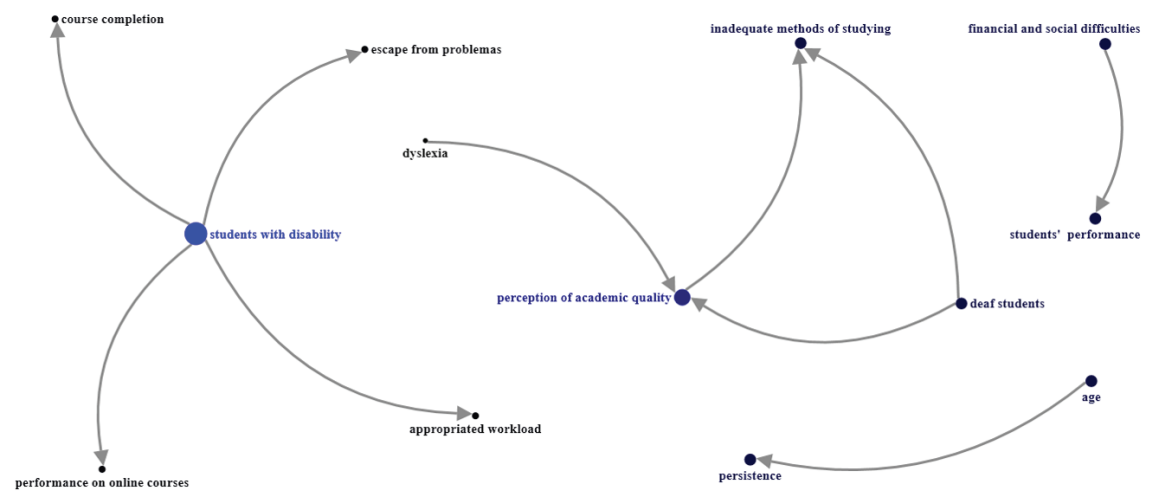

O vértice mais importante foi estudantes com deficiência, pois alcançou maior escore na métrica PageRank (2,3), estabelecendo conexão com 4 outros vértices do multigrafo. $\mathrm{O}$ vértice estudante com deficiência tem uma relação negativa com os vértices carga de trabalho apropriada, com a performance nos cursos online, assim como,na conclusão do curso superior e fuga de problemas. No que se refere à variável carga de trabalho apropriada, o estudo de Jelfs e Richardson (2010) aponta para os discentes 
com dificuldades mentais que tiveram relação (efeito) negativa com carga de trabalho apropriada ( $\mathrm{p}<.05 ; \beta-0.08)$. Entendeu-se que esses alunos acham mais difícil descobrir o que se espera deles no ensino superior, e, como consequência, adotam uma estratégia de memorização de estudo, considerada inadequada quando se trata de questôes tấo complexas quanto as que são discutidas no ensino superior.

Em se tratando do bem estar psicológico, Atabey et al. (2011) examinaram as influências do crescimento de estresse e da angústia psicológica de alunos com deficiência. Os resultados indicaram que a variável tipo de deficiência teve relaçáo (efeito) negativa significativa com fuga de problemas ( $\mathrm{p}<.05 ; \beta-0.37$ ), isto indica que alunos com deficiência fogem menos do enfretamento dos problemas, pois a despeito das dificuldades tentam superar as limitaçôes, focando no problema.

No que se refere à variável performance nos cursos online, Roberts, Crittenden e Crittenden (2011) investigaram as experiências de alunos com deficiência acerca de suas percepçóes para ter sucesso em cursos online. Os resultados revelaram que estudantes com deficiência percebem suas incapacidades gerando efeito (relação) negativo sobre sua capacidade de ter sucesso, ou seja, esses universitários com deficiência têm menor capacidade de ter sucesso em cursos online.

O segundo vértice mais importante foi percepçâo da qualidade acadêmica, com PageRank de 1,4 e com conexão direta com 3 diferentes vértices. $\mathrm{O}$ vértice percep̧̧ão da qualidade acadêmica está negativamente relacionado com o vértice métodos inadequados de estudo, assim como a variável estudantes com deficiência auditiva está relacionada negativamente com os vértices percepção da qualidade acadêmica e métodos inadequados de estudo. O vértice dislexia tem uma relação negativa com a percepção da qualidade acadêmica.

Neste sentido, o estudo realizado por Richardson, Barnes e Fleming (2004) procurou investigar a relação entre as abordagens de estudo e a percepção do estudante com e sem deficiência auditiva acerca da qualidade acadêmica. Observou-se que a percepção de qualidade acadêmica dos alunos surdos apresentou correlação negativa com formas indesejadas de estudo, demonstrando que o impacto de variáveis contextuais sobre as abordagens (maneiras) de estudo por parte dos alunos é mediada pela forma como percebem o ambiente. Isto significa que a percepção da qualidade acadêmica determina as formas de estudo no ensino superior. Neste caso específico, quanto melhores e mais elevadas forem as percepçóes dos alunos em relaçáa à qualidade acadêmica, escolheráo menos formas indesejáveis de aprendizagem.

Outro estudo, de Jelfs e Richardson (2010), investigou alunos com e sem deficiência sobre suas abordagens de estudo e das percepçóes acerca da qualidade acadêmica dos cursos da Universidade Aberta do Reino Unido. Estudantes com dislexia tiveram relação (efeito) negativa com percepção de qualidade acadêmica $(\mathrm{p}<.001 ; \beta$ -0.09), indicando que alunos com dislexia têm menor percepção da qualidade acadêmica e, como consequência, são levados a adotar uma abordagem superficial, isto é, a de memorização de estudo, considerada inadequada. 
No multigrafo (Figura 2), observou-se que houve dois pares de vértices isolados e de menos importância. O vértice dificuldades financeiras e sociais teve uma relação negativa com performance do estudante, assim como o vértice idade teve um efeito negativo com a variável persistência. Neste sentido, o estudo de Richardson (2010) teve por objetivo comparar os resultados obtidos da taxa de conclusão dos alunos com e sem deficiência que frequentaram os cursos de ensino à distância da Universidade Aberta do Reino Unido. No que se refere às taxas de conclusão de curso, os alunos com deficiência demonstraram concluir menos cursos de nível superior, pois a privação socioeconômica foi correlacionada negativamente com o desempenho dos alunos. Percebeu-se índices de aprovação mais baixa entre acadêmicos de classes socioeconômicas mais pobres, então quanto maior for a privação financeira, menor será o desempenho dos estudantes.

No vértice idade, a idade do aluno com deficiência tem um efeito negativo na variável persistência. Este efeito negativo foi analisado no estudo de Mamiseishvili e Koch (2011) que examinaram a percepção de estudantes universitários com deficiência matriculados no segundo ano da graduação e os fatores que influenciaram na persistência dos mesmos para concluir o curso superior. O estudo revelou que a variável idade apresentou relação (efeito) negativa (o) significativa com persistência de alunos com deficiência no primeiro e no segundo ano do curso ( $\mathrm{p}<.05 ; \beta-0.18$ ). Isto significa que alunos mais velhos são menos persistentes nos primeiros anos do curso superior.

\section{Discussões}

Nas variáveis dos artigos analisados no Grafo das Correlaçóes Positivas, percebeu-se que a revelação da deficiência por parte do aluno ao se matricular na instituição é de fundamental importância para o seu sucesso acadêmico. Com esta informaçáo, a universidade poderá se organizar para oferecer acomodaçóes adequadas, métodos apropriados de ensino, apoio especializado ao estudante, tecnologia assistiva e espaços acessíveis para que os mesmos possam desenvolver suas habilidades acadêmicas a contento. As instituiçôes de ensino superior devem desenvolver açóes que possibilitem aos alunos serviços educacionais adequados com uma infraestrutura condizente para os vários tipos de deficiência, bem como a capacitação de professores com métodos e estilos apropriados de ensino.

Quanto às variáveis analisadas relacionadas às questóes da acessibilidade arquitetônica das instituiçôes de ensino superior, percebeu-se a necessidade de garantir que os alunos com deficiência tenham acesso aos diferentes espaços da universidade. Neste sentido, a Convenção Internacional das Pessoas com Deficiência assegura a acessibilidade aos deficientes aos meios físico, social, econômico e cultural (ONU, 2006). Tal procedimento permite que estudantes tenham garantidos o acesso livre às diversas dependências da instituição, utilizando os equipamentos e instalaçốes que possam auxiliar os mesmos na sua performance acadêmica e social.

Em relação às variáveis relacionadas à acessibilidade pedagógica, as instituições de ensino superior precisam considerar as diferentes necessidades de aprendizagem 
de seus alunos com deficiência. No entanto, para que isso ocorra, é necessário que os docentes tenham uma formação acadêmica com conhecimentos na área da educação inclusiva que lhes permitam ensinar e promover a aprendizagem dos alunos. Neste sentido, a Declaraçáo de Salamanca (UNESCO, 1994, p. 27) esclarece no item Recrutamento e Treino de Pessoal Docente que o professor deve ter uma orientação positiva frente à deficiência. Tal postura requer habilidades e conhecimentos que dizem respeito à boa prática de ensino que envolve avaliação das necessidades especiais, adaptação do currículo e conhecimento acerca das tecnologias assistivas.

Nos dados apresentados no Grafo das Correlaçóes Negativas, constatou-se em alguns estudos, a insatisfação sentida pelos alunos com deficiência acerca de suas necessidades ao enfrentarem limitaçóes no contexto das instituiçóes de ensino superior. Na variável analisada acerca dos métodos inadequados de estudo, observou-se a preocupaçáo do estudante com deficiência auditiva acerca do seu processo de aprendizagem. Tal processo requer profissionais capacitados para avaliar as necessidades especiais de cada um, de adaptar o conteúdo do programa de estudos, de recorrer à ajuda da tecnologia e de individualizar os procedimentos pedagógicos às aptidóes de cada estudante (UNESCO, 1994, p. 26).

Os estudantes com deficiência visual e auditiva necessitam das Tecnologias Assistivas (TA) para seu aprendizado. No que se refere ao domínio da acessibilidade na web, as tecnologias assistivas, que são os hardwares, os periféricos e os softwares e/ou programas especiais, precisam estar disponíveis, permitindo o acesso à Internet. Tais equipamentos necessitam de leitores de tela, sintetizadores de voz, ampliadores de tela, programas de comando de voz, teclados e mouses especiais, controlados por um joystick, entre outros (QUEIROZ, 2006).

Em relação às dificuldades financeiras e sociais, Richardson (2010) constatou que esta variável apresenta uma correlação negativa no desempenho acadêmico dos estudantes. A Declaração Mundial sobre Educação para Todos, no artigo oitavo, esclarece que os requisitos para garantir uma educaçáo para todos incluem o desenvolvimento de uma política contextualizada de apoio, isto é, políticas de apoio no que se referem ao setor econômico, social e cultural, visando, assim, a concretizaçáo da educação básica para a promoção individual e social. Já no artigo nono, da referida Declaração, ao mencionar a mobilização de recursos, a mesma se refere aos recursos humanos, públicos, privados e voluntários. Desse modo, a sociedade tem responsabilidade com a educação e o papel do setor público "é atrair recursos de todos os órgãos governamentais responsáveis pelo desenvolvimento humano, mediante o aumento em valores absolutos e relativos, das dotaçôes orçamentárias aos serviços da educação básica" (UNESCO, 1990, p. 7-8).

\section{Considerações finais}

Esta revisão sistemática possui algumas limitações decorrentes das buscas dos artigos derivados da base de dados do Portal de Periódicos - CAPES, na qual possui um acervo de pesquisas a nível internacional. Sugere-se que futuras pesquisas ampliem suas buscas utilizando outras bases de dados e em outros idiomas. 
Com base nos dados encontrados no grafo das correlaçóes negativas contidas nesta revisão sistemática, recomenda-se, ainda, que futuras pesquisas sejam realizadas acerca da capacitaçáo dos professores e na disponibilidade dos cursos online. Há a necessidade de qualificar o professor para que adote métodos adequados de ensino e aprendizagem referentes a cada tipo de deficiência. É necessário que as instituiçôes de ensino superior invistam nos cursos de capacitação de docentes na área da inclusão. Em relação aos cursos online oferecidos pelas universidades, as mesmas devem estar equipadas com tecnologias assistivas e, assim, promover a autonomia do aluno com deficiência, permitindo que ele estabeleça relaçôes com o mundo virtual.

Por fim, a análise desenvolvida nesta revisão sistemática possibilitou contribuir para a construção de conhecimento acerca da inclusão do aluno com deficiência no ensino superior. Embora a matrícula e a presença do acadêmico estejam legalmente amparadas por lei, certas atitudes por parte da universidade podem favorecer a inclusão, assim como podem dificultar a participação do mesmo no contexto universitário.

\section{Referências}

ARANHA, M. S. F. (Org.). Educação inclusiva: a escola. Brasília: MEC, Secretaria de Educação Especial, p. 26, 2004.

ATABEY, M. K.; et al. Psychological wellbeing of Turkish university students with physical impairments: An evaluation within the stress-vulnerability paradigm. International Journal of Psychology, v. 46, n. 2, p. 106$118,2011$.

AZEVEDO, R. S. Sobrecarga do cuidador informal da pessoa idosa frágil: uma revisão sistemática. 2010. 66 f. Dissertação (Mestrado em Saúde e Enfermagem) - Escola de Enfermagem, Universidade Federal de Minas Gerais, Belo Horizonte, 2010.

BRAK, L. B.; LECHENBERGER, D.; LAN, W. Y. Accommodation strategies of college students with disabilities. The Qualitative Report, n.15, p. 411-429, 2010.

FISCHER, J. Inclusão escolar de acadêmicos com deficiência na universidade: Possibilidades e desafios. 2010. Disponível em: <http://www.anped.org.br> Acesso em: maio de 2013.

FREIRE, S. Um olhar sobre a inclusão. Revista da Educaçáo, v. 16, n. 1, p. 5-20, 2008.

HADJIKAKOU, K.; POLYCARPOU, V.; HADJILIA, A. The Experiences of students with mobility disabilities in Cypriot Higher Education Institutions: Listening to their voices. International Journal of Disability, Development and Education, v. 54, n. 4, p. 403-426, 2010.

HEIMAN, T.; SHEMESH, D. O. Students with LD in Higher Education: Use and Contribution of Assistive Technology and Website Courses and Their Correlation to Students' Hope and Well-Being. Journal of Learning Disabilities, v. 45, n. 4, p. 308-318, 2012.

JELFS, A.; RICHARDSON, J. T. E. Perceptions of academic quality and approaches to studying among disabled and nondisabled students in distance education. Studies in Higher Education, v. 35, n. 5, p. 593-607, 2010.

MAMISEISHVILI, K.; KOCH, C. L. First to second year persistence of students with disabilities in postsecondary institutions in the United States. Rehabil Couns Bull, v. 2, n. 54, p. 93-105, 2011.

ONU. Convençáa sobre os direitos das pessoas com deficiência, 2006. Disponível em: <http://www.un.org/ disabilities/convention/conventionfull.shtml>. Acesso em: set. 2011.

QUEIROZ, M. A. Acessibilidade Web: tudo tem sua primeira vez, 2006. Disponível em: <http://www.bengalalegal.com/capitulomaq.php>. Acesso em: abr. 2012.

QUINLAN, M. M., BATES, B. R.; ANGELL, M. E. What can I do to help?’: Postsecondary students with learning disabilities' perceptions of instructors' classroom accommodations. Journal of Research in Special Educational Needs, v.12, n. 4, p. 224-233, 2012. 
Rosamaria Reo Pereira - Simone Souza da Costa Silva - Rosana Assef Faciola - Fernando

Augusto Ramos Pontes - Maély Ferreira Holanda Ramos

RICHARDSON, J. T. E.; BARNES, L.; FLEMING, J. Approaches to studying and perceptions of academic quality in deaf and hearing students in higher education. Deafness and Education International, v. 6, n. 2, p. 100-123, 2004.

RICHARDSON, J. T. E. Course completion and attainment in disabled students taking courses with the Open University UK. Open Learning, v. 25, n. 2, p. 81-94, 2010.

RIDDELL, S.; et al. Managerialism and equalities: tensions within widening access policy and practice for disabled students in UK universities. Higher Education, v. 54, p. 615-628, 2007.

ROBERTS, J. B.; CRITTENDEN, L. A.; CRITTENDEN, J. C. Students with disabilities and online learning: A cross-institutional study of perceived satisfaction with accessibility compliance and services. Internet and Higher Education, v.14, p. 242-250, 2011.

STAMPOLTZIS, A.; et al. Learning sensory modalities and educational characteristics of Greek dyslexic and non dyslexic university students. Electronic Journal of Research in Educational Psychology, v. 8, n. 2, p. 561-580, 2010.

TAYLOR, M.; BASKETT, M.; WREN, C. Managing the transition to university for disabled students. Education and Training, v. 52, n, 2, p.165-175, 2010.

UNESCO. Declaraçáo Mundial de Educaçáo para Todos. Plano de ação para satisfazer as necessidades básicas de aprendizagem, Tailândia, 1990.

Conferência Mundial de Educaçáo Especial. Declaração de Salamanca, 1994. Disponível em: <http:// portal.mec.gov.br/seesp/arquivos/pdf/salamanca.pdf>. Acesso em: abr. 2012. 1999.

Declaração Mundial sobre educação superior no século XXI, 1998. Săo Gonçalo: UNIVERSO,

ZHANG, D.; et al. University faculty knowledge, beliefs, and practices in providing reasonable accommodations to students with disabilities. Remedial and Special Education, v. 31, n. 4, p. 276-286, 2010.

\section{Correspondência}

Rosamaria Reo Pereira - Universidade Federal do Pará, Faculdade de Letras Estrangeiras Modernas. Rua Augusto Correa n. 1, Guamá, CEP: 66075-110 - Belém, Pará - Brasil.

E-mail: rosareoufpa@gmail.com - symon.ufpa@gmail.com - rosanassef@gmail.com - farp1304@hotmail.com - maelyramos@hotmail.com

Recebido em 30 de abril de 2015

Aprovado em 21 de julho de 2015 